\title{
Speakers's corner
}

\section{The essence of community}

There is an increase of self interests and turf issues, in the health field.

The reply to change is "We can't do that!" It reflects the inability and fear of exploring "alternate scenarios". It demands dreaming, speculation and surprise.

This response of politicians, unwilling to take risks, is an excuse for leadership, using polls of public opinion. A leader is a coach, enabler, facilitator to find new stories. Leaders are educators.

Ordinary problems of people are ignored. Problems in communities are: food, shelter, health care, education, jobs, racism, and living with a diverse uncaring world. Ignoring this, makes people superfluous.

Our preoccupation is with "I", ignoring "WE". An absence of the whole community. Seeing fragments, some say, is human nature. At our beginning levels of psychological and moral development we only survive. Gradually, with maturity, we create new stories, and can see the whole.

What is it about America that is so self interested, full of violence, so anti-government, and, anti-community. One cannot personally, remain healthy, when one organ is "sick." In our communities organisms, we focus on parts, closing our eyes to the poor, leaving to others the job of caring for them. Physicians cutting time with patients, cannot see the whole, only the payable symptom.

Our ghettos are where "those people" live, ignoring street kids, wishing they behave, sending them to prison, or to die early. We poison lakes to kill fish, and damage the drinking supply, destroying their economy. We deal with the symptom, ignoring underlying questions. How do the symptoms appear, and how can we prevent it?

Early immigrants to the USA came because of tyranny of governments, poverty, or as slaves. They fought for freedom to be an " $I$ ". They fought the British. The Tories, or lovers of government went to Canada. Canadians state that " they talk of peace order, and good government." Americans, of life, liberty and the pursuit of happiness."

Going west, when things failed, blaming others, the new immigrants, minorities, and people of colour, anyone but looking at themselves, and our values. There was the frontier. We could afford to waste.

Emerging from the great depression was the outside threat, and war, brought us together as a unified country.

A science fiction story tells how Russia and the USA built up capabilities with weapons. The computers of each side were excellent, they predicted the other's moves, and responded automatically. One day both countries' computers found enemies in outer space. They had a unified response. The computers created the enemy to achieve a common objective, peace.

Can we find other ways towards shared values? Small, often isolated programmes have different stories. Healthy Cities, Healthy Communities, Liveable, Sustainable, Safe, Ecological Cities, are making a dent, ignored by big politics. Bologna has a sense of community. "It is our city!" " $W E$ " is used, to support education, housing and community infrastructure. The piazzas are filled with people talking, playing, or doing business.

Collaborative action, and resources lead to real solutions. The best schools, health programmes and communities occur when "WE" continue to learn, educate each other, thinking holistically, daring to dream, and forgetting our turf. We must honour those persons who think differently, who don't play the game. Many organisations and families, demand conformity and deny deviance. Control, the powers of authority, can't ignore those who dream.

Another way to shared values, is to start community-wide dialogues, asking for visions of a valued future, respecting the commonality in Judeo-Christian, Islamic, and Eastern spiritual beliefs. De-emphasising the differences, allows exploration of similarities, and common traits.

Business, science, technology, culture, and governments, must similarly explore their common values, visions, and differences, to permit new patterns. Diverse cultures of the past Middle East, made it the hot house of Western civilisation. Similar, are current diverse cities.

University of California at Berkeley, USA
LEONARD DUHL 